\title{
Erratum to: Characteristics and outcomes of advanced cancer patients who miss outpatient supportive care consult appointments
}

\author{
Marvin Omar Delgado Guay • Silvia Tanzi • \\ Maria Teresa San Miguel Arregui • Gary Chisholm • \\ Maxine G. De la Cruz • Eduardo Bruera
}

Published online: 25 July 2014

(C) Springer-Verlag Berlin Heidelberg 2014

\section{Erratum to: Support Care Cancer}

DOI 10.1007/s00520-014-2254-8

The original version of this article unfortunately contained errors in the citation of the correspondent author and coauthors last names. The correct citation for the correspondent author is DELGADO GUAY, MO and the correct citation name for the co-authors is as follows: SAN MIGUEL ARREGUI, MT and DE LA CRUZ, MG.

The online version of the original article can be found at http://dx.doi.org/ 10.1007/s00520-014-2254-8

M. O. Delgado Guay $(\bowtie) \cdot$ M. T. San Miguel Arregui •

G. Chisholm • M. G. De la Cruz • E. Bruera

Palliative Care and Rehabilitation Medicine, Unit 008, The

University of Texas MD Anderson Cancer Center, 1515 Holcombe

Blvd., Houston, TX 77030-4009, USA

e-mail: marvin.delgado@mdanderson.org

S. Tanzi

IRCCS Arcispedale Santa Maria Nuova, Reggio Emilia, Italy 